\title{
DECISIONES RAZONABLES. EL USO DEL PRINCIPIO DE RAZONABILIDAD EN LA MOTIVACIÓN ADMINISTRATIVA
}

\section{Ignacio A. Boulin Victoria}

Ciudad Autónoma de Buenos Aires: Marcial Pons Argentina, 2014, 197 páginas.

Decisiones razonables constituye una obra intrépida y original dentro del derecho administrativo argentino. Ignacio Boulin Victoria decide someter a escrutinio una serie de conceptos fundamentales y, por ende, harto analizados de la disciplina -como la discrecionalidad o la razonabilidad-, y abocarse al estudio del ejercicio de la función administrativa desde un prisma innovador y, ante todo, necesario. Lejos de ser condescendiente o de amedrentarse por el desafío, como destaca Alberto Bianchi en el prólogo, el autor nos enseña que incluso los temas clásicos del derecho pueden ser revisitados, si existe un espíritu ingenioso y crítico dispuesto a ello.

Pensar el derecho administrativo en un país como la Argentina demanda una profunda actividad intelectual, del tenor de la aquí practicada. El ejercicio del poder político y el modo en que este se traduce en decisiones administrativas son abordados inteligente y sesudamente en la obra, que, sin quedarse en una mera descripción del asunto, invita a pensar formas de tornarlos más transparentes y democráticos. Así, su permanente -y recurrente- actualidad torna necesaria su consulta y obliga a reseñarla, aun pasados algunos años de publicada.

Carlos Nino, en su célebre Un país al margen de la ley, sostenía que existía una clara tendencia argentina -del Estado como de los particulares- a la "anomia" y, en particular, a lo que llamaba la "anomia boba" y la ineficiencia, con fuertes repercusiones sobre nuestro desarrollo. La adopción de decisiones razonables, en tal sentido, se proyecta como una respuesta necesaria para dar cuenta del fenómeno y obligar a la Administración a desechar la arbitrariedad y favorecer, paralelamente, la dignidad humana y la eficiencia. Como destaca Boulin, el siglo XXI debe ser el de la "buena administración", que brinde la posibilidad de responder globalmente a los problemas generales. 
La introducción de la obra y el primero de sus ocho capítulos deben ser analizados en conjunto, colocando el foco en dos puntos que aparecen como esenciales y repercuten en el devenir del texto. Por un lado, en la necesidad de cambiar el enfoque sobre el modo de abordar el derecho administrativo; pensar y estudiar el funcionamiento de la Administración a la hora de la elaboración de las decisiones públicas - para mejorarlas-y no ceñirlo exclusivamente al estudio de su control judicial.

Por otra parte, detenerse en la necesaria ligazón que debe existir entre el concepto de "democracia" y el de "administración pública". En efecto, como allí se expone, esta última no puede -tampoco el derecho administrativo- ser desvinculada del contexto democrático, sino que ello es fundamental para arribar a decisiones que propendan a la participación y la discusión pública, el respeto de los derechos humanos y el fortalecimiento del texto constitucional.

Es innegable, manifiesta el autor, el rol preponderante que ha adquirido el Poder Ejecutivo y la incidencia habitual que suele tener sobre los derechos, siendo el factor regulador por excelencia de la vida social. Entonces, con el objeto de evitar lesionarlos arbitrariamente, la actividad administrativa debe actuar con miras a un fin - por el caso, el bienestar general y la promoción de los derechos- y, para ello, hacerlo en base a razones. A tal efecto, un modo de encontrar razones para arribar a decisiones correctas es la deliberación pública.

Evocando concepciones propias de pensadores de la democracia deliberativa -como el propio Nino-, Boulin expone, certeramente, los beneficios que el debate y el intercambio de opiniones pueden introducir sobre el quehacer administrativo. En detrimento de la anomia, eliminar errores en el razonamiento o tomar en cuenta las diversas posiciones y necesidades sociales conduce a una mayor eficiencia y acatamiento de las decisiones, como también a un aumento en la -crítica- legitimidad democrática de la Administración Pública. Como sostiene, en definitiva, buenas decisiones y democracia son nociones que van de la mano.

Ello así, en el capítulo segundo la obra nos invita a repensar un concepto basal en el derecho administrativo: la discrecionalidad. Tradicionalmente, bajo el paradigma centrado en el control judicial, el freno y la reducción de la discrecionalidad tornaron puntos primordiales dentro de la disciplina. No obstante, tal perspectiva, sostiene el autor, olvidó que el mero ejercicio del poder implica discrecionalidad y que ella no es intrínsecamente negativa. Dependiendo de quién la utilice, puede dar lugar a abusos o a un desenvolvimiento eficiente de la Administración.

Sobre estas bases, Boulin propone replantear la idea de la actividad admi- 
nistrativa discrecional. Para ello, invita a dejar de pensar que el núcleo de la decisión discrecional descansa en la posibilidad de la Administración de optar entre varias alternativas igualmente válidas. Por el contrario, si las alternativas son diferentes, no es posible identificarlas como iguales y, por consiguiente, indiferentes para el Derecho. Hacerlo vulnera el principio lógico de identidad. Algunas de las opciones serán más convenientes en alguna de sus propiedades y menos en otras. En definitiva, no todas las posibles alternativas son iguales ni los funcionarios pueden elegir cualquiera de ellas. Siempre existirá una opción que, en la subjetividad del funcionario y comparada con una decisión óptima, será la más propicia.

De este modo, el autor redefine a la discrecionalidad administrativa como una forma de la actividad mediante la cual la norma atributiva de competencia otorga a la Administración la facultad de decidir cuál de todas las alternativas posibles, dentro del marco de lo presumiblemente razonable, es la más conveniente en el caso concreto y respecto al particular fin buscado. Tal concepción, por lo demás, se proyecta críticamente sobre la noción del "concepto jurídico indeterminado" y exige del derecho transparencia en la toma de decisiones.

Pues bien, avanzando sobre el capítulo tercero, punto neurálgico de la obra, Boulin destaca que la discrecionalidad requiere de una debida argumentación de las decisiones adoptadas, de modo de demostrar su conveniencia, y propone al principio de razonabilidad como herramienta para avanzar sobre este desafío. Aquel procura ordenar los medios por los cuales una actuación procura un fin -permitido constitucionalmente- de forma tal de no afectar el contenido esencial de los derechos en su acción. La medida estatal, en este sentido, debe ser evaluada a la luz de un control centrado en tres subprincipios de la razonabilidad: la idoneidad, la necesidad y la proporcionalidad.

Empero, el autor va más allá. El control de los actos estatales es el campo más emblemático de aplicación del principio de razonabilidad y, en esta función, este permite delimitar la existencia de una garantía del contenido esencial de los derechos, además de otorgar publicidad al proceso decisorio. Al examen tripartito clásico, entonces, debe adicionársele la verificación de la indemnidad de esa garantía que, al ser un límite infranqueable, actúa como un complemento de la proporcionalidad. No obstante, debe ser estudiada, expone Boulin, en su funcionamiento real. El ejercicio razonable de un derecho en un caso puede ser irrazonable en otro. La decisión debe conceder la razón a la posición que la tenga en ese caso, sin inmolar los derechos en el altar del bien común o de la razón del más fuerte. 
Con ello como puente, en el capítulo cuarto la obra analiza la relación entre el control judicial y el principio de razonabilidad. Y lo hace con una arriesgada afirmación: el actuar de los jueces encorseta y debilita su vigor. En efecto, el marco constitucional de actuación de los magistrados le resta potencia, mientras que plantear un sistema más robusto puede derivar en la sustitución de la discrecionalidad administrativa por el -siempre temido-gobierno de los jueces.

Los tribunales solo son capaces de realizar un control negativo de las medidas adoptadas y desechar aquellas absolutamente inadecuadas; no pueden sustituir a la Administración en su temperamento y poseen un conocimiento parcial del asunto ceñido a las particularidades y tiempos del caso; y sólo pueden declarar desproporcionada la medida administrativa que, en forma patente, afecte el derecho fundamental con una mayor intensidad que aquella con la que favorece el principio constitucional que pretende conseguir. Asimismo, también presenta dificultades para definir el contenido esencial de un derecho o de un bien público, aunque esta no es exclusiva del actuar judicial.

Lo que debe procurarse, propone Boulin, es que la Administración aplique y utilice la potencia del principio de razonabilidad en la motivación de sus decisiones. Tal es la labor sobre la que se profundiza en los capítulos quinto y sexto. La motivación, exigencia constitucional y legal, transparenta y legitima el proceso decisional, garantiza su escrutinio y permite su optimización, como también el de sus resultados. Actúa, según el autor, como un antídoto para consolidar una Administración democrática.

Bajo la original concepción de la discrecionalidad planteada, la motivación adquiere un tenor especial. Permite observar el ejercicio y el dinamismo del principio de razonabilidad en el caso y traduce, a fin de cuentas, las razones por las cuales la decisión escogida constituye la más conveniente, con la consiguiente mejora en el actuar administrativo que ello implica.

En definitiva, compete a los funcionarios explicar porqué consideran que la solución que imponen es justa y solo a partir de una apropiada motivación podrá facilitarse el control judicial. Este, en la propuesta de Boulin, adquirirá connotaciones particulares, con un estricto respeto por las atribuciones constitucionales de cada poder, pero con una mayor incidencia sobre los momentos del procedimiento administrativo.

En el capítulo séptimo, el autor introduce la experiencia de la Oficina de Información y Asuntos Regulatorios estadounidense, como muestra de un órgano estatal diseñado para que la Administración piense y adopte decisiones razonables, valorando costos, beneficios y alternativas. Su mantenimiento a lo largo de 
distintos gobiernos, señala, da la pauta de la existencia de un consenso sobre la utilidad de implementar mecanismos que faciliten regulaciones razonables.

Finalmente, en el último capítulo, dedicado a las conclusiones, el autor realiza un resumen de las principales ideas de la obra y destaca los desafíos que importa la nueva conflictividad social. Ese marco, postula, exige salidas innovadoras que fortalezcan la democracia y decisiones razonadas con Administraciones transparentes que den cuenta de sus actos.

Boulin Victoria nos enseña que, a veces, deteniéndonos a pensar -y no a repetir- se pueden proponer desde el derecho, aun de modo breve, diagnósticos claros y soluciones a problemas relevantes. Es posible hacerlo, además, desde un paradigma innovador, ingresando en la "caja negra" de la Administración, analizando cómo funciona en la realidad y cuáles son sus limitaciones, capacidades e interconexión con el ambiente.

Es misión del derecho, como sostiene el autor, saldar la deuda de razonabilidad que el poder y la política han contraído con la sociedad. Es misión de los juristas, agregamos, buscar soluciones inteligentes para ello. Esta labor, particularmente en la Argentina, repercute con profundidad y nos conmina a avanzar, dejando atrás aquel país - parafraseando a Nino- al margen de la "razonabilidad".

\section{Juan Martín Scarramberg}

Universidad de Buenos Aires

juanmartinsca@gmail.com 
